\title{
THE BRAIN CASE AND ENDOCRANIAL CAST OF ERYOPS MEGACEPHALUS (COPE)
}

\author{
W. T. DEMPSTER \\ Anatomical Laboratory, University of Michigan \\ TWELVE FIGURES \\ (Accepted for publication September 10, 1934)
}

In view of the probable phylogenetic position of the Stegocephalia ${ }^{1}$ as ancestors of both reptiles and amphibians, the general osteology of these animals has been fairly well worked out. The brain case and endocranial anatomy, however, are not as well understood in these forms as in many phylogenetically less important fossils. The more primitive

${ }^{1}$ A few points may help in orienting the reader who is unaequainted with the fossil record of the vertebrates. The Stegocephalia are considered as forming an order of the Amphibia equivalent to the modern Gymnophiona, Urodela and Anura. They were salamander or lizard-like in body form, but were generally much larger than modern Amphibia. Both aquatic and terrestrial forms appeared. The animals were present in the Carboniferous and persisted through the Permian and Triassic periods when the group became extinct. In their evolution, they became modified into several morphological varieties (suborder, Temnospondyli with a number of families grouped as Embolomeri, Rhachitomi, and Stereospondyli; suborder, Lepospondyli; suborder, Phyllospondyli; and suborder, Adelospondyli). The modern Amphibia probably arose as a modification of some stegocephalian form. The primitive and extinct reptilian order Cotylosauria likewise shows similarities to the Stegoeephalia which suggest genetic relationships. Although the precise parent forms of the Amphibia and Reptilia are undetermined or controverted, the Stegocephalia as a group possess osteological features which give an insight into the primitive amphibio-reptilian stock. Unfortunately, the soft structures, such as museles, nerves and viscera are unknown. Attempts, however, have already been made to reconstruct portions of the musculature from the areas on the bones for muscle attachment. The present paper is designed primarily to provide some basis for inferring the nature of the endocranial anatomy of the primitive tetrapod. Though Eryops is undoubtedly not in the direct line of ascent for either amphibian or reptilian stocks, more may be learned from this genus than from some of the more generalized but related genera. 
forms (Embolomeri and early Rhachitomi) are, on the whole, represented by specimens which, necause of their scarcity and state of preservation, are often not suitable for detailed studies. The later forms of the Permian and Triassic possess brain cases with incomplete osseous walls, the brains ordinarily being surrounded, as they are in modern reptiles, by fibrous or cartilaginous walls. These weak walls were not preserved by fossilization, and, for this reason, few specimens are sufficiently complete to allow extensive study of the brain case. Nevertheless, attention has been directed to the brain cases of such forms as: Capitosaurus and Trematosaurus (Watson, '20), Paleogyrinus and Eogyrinus (Watson, '26), Archegosaurus (Hofker, '27), Buettneria (Case, '31), Mastodonsaurus (Pfannenstiel, '32) and Trimerorhachis (Case, '35). No studies, however, have yet been made on endocranial casts of these forms. In fact, the Stegocephalia form one of the few groups of fossil tetrapods in which such studies have not yet been made.

Unlike most rhachitomous Stegocephalia, Eryops megacephalus (Cope), perhaps the best known of the American forms, possesses a complete bony envelope for the endocranial cavity. Although the brain case region of the skulls is frequently broken or distorted, a satisfactory survey is made possible by the relatively large number of skulls in several American museums. The first study of the Eryops brain case was that of von Huene ('12 and '13), and this was supplemented by Broom ('13) and later by Watson ('16).' Despite competent study, the work of these men is inadequate or contradictory in several details. The function of the present paper, therefore, is to reconstruct the neurocranium from a consideration of hitherto unstudied material, and, in addition, to present an account of the endocranial anatomy.

\footnotetext{
${ }^{2}$ When these three authors are mentioned hereafter without the date of publication, these specific papers are implied. The earlier studies on the skull by Broili (1899), Branson ('05) and Case ('11) dealt with features other than the brain case.
} 


\section{MATERIAL}

The Eryops material of the University of Michigan Museum of Paleontology formed the basis for this investigation. Two specimens borrowed from the American Museum of Natural History likewise received more or less intensive study and the information obtained from this material was supplemented (during a visit to New York and Chicago) by a brief study of the Eryops fossils in the American Museum and in the Walker Museum of The University of Chicago. ${ }^{3}$

The hard Permian limestone matrix was cleared from the more useful fossils by sharpened awls and by drills, burrs and carborundum wheels of the sort used by dentists. In three instances, the brain cases were sectioned in various regions. These sections, together with some fragments and weathered isolated bony elements, were of utmost value in reconstructing the osteology of regions not well shown in the more complete material.

Since the fossilization process commonly introduced defects and asymmetry, direct endocranial casts ordinarily showed distortion of one sort or another. Accordingly, an indirect procedure resulted in more satisfactory casts.

By this method, glue mold impressions were made of the endocranial walls of the various crania. After comparing the impressions from different specimens, some of which showed features which were absent in others, an 'ideal' reconstruction was modeled in wax. This represented in one bilaterally symmetrical mass characteristics which were obviously undistorted or were identically duplicated in several specimens. Then, a plaster negative was made of the modeled reconstruction. This negative was compared with the actual cranial walls and corrected where necessary. Finally, a cast was made of the corrected negative. This cast, which is an

s This investigation was instigated at the suggestion of Prof. E. C. Case, of the University of Michigan Paleontological Laboratory, and he has generously provided material and working facilities as well as invaluable criticism. The Eryops material of the American Museum was made available through the courtesy of Dr. Walter Granger. Mr. Barnum Brown also pernitted me to borrow material. Access to the Walker Museum was made possible by Dr. Carey Croneis. 
approximation to the kind of cast which could be obtained from direct casting from perfect walls, is the one illustrated in the text.

\section{THE BRAIN CASE}

General osteological features. The available descriptions of the Eryops brain case are sufficiently detailed to render

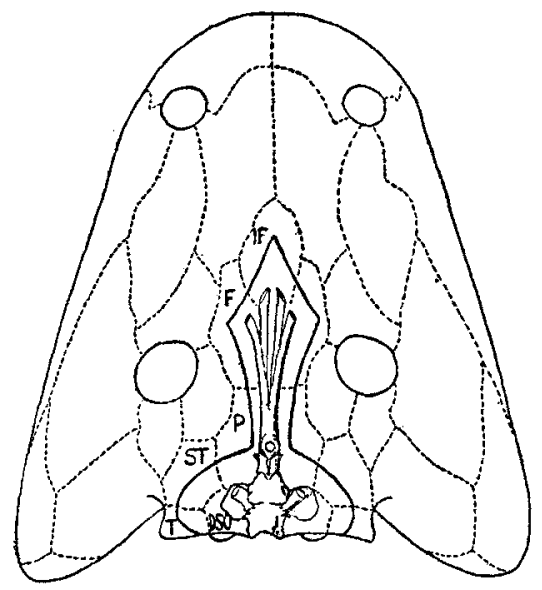

Fig. 1 Diagram of dorsal aspect of Eryops skull. The size and general contour of the brain cast, eranial nerves and internal ear are shown in their relation to the skull as a whole. The heavy outline indicates the size of the brain case; the bones of the skull roof above the brain ease are: interfrontal, $I F$; frontal, $F$; parietal, $P$; supratemporal, $S T$; dermsupraoccipital, DSO; tabulare, T. $\times \frac{1}{8}$.

unnecessary elaborate descriptions of individual bones. Consequently, semi-diagrammatic illustrations ${ }^{4}$ will serve to outline the author's interpretation of the general osteology, while specific attention is directed to several points which have been obscure in the material previously studied.

Some difference of opinion appears in the descriptions by von Huene, Broom and Watson of isolated bony elements, and this is due primarily to the fused condition of the bones. Of

- The illustrations, excluding figures 1 and 7 , are composite sketches in which each feature, with the exception of the pineal and diencephalic regions, has been corroborated by several speeimens. 
the eleven bones ${ }^{5}$ comprising the brain case, only four, the parasphenoid, the basioccipital, and the paired epipterygoids and stapes, are distinct and unfused. Their boundaries and articulations are wholly clear. The remaining bones, however, are inseparably united to others to form two larger bony units, which are delimited by sutures externally, but are confluent on their endocranial faces. The more anterior

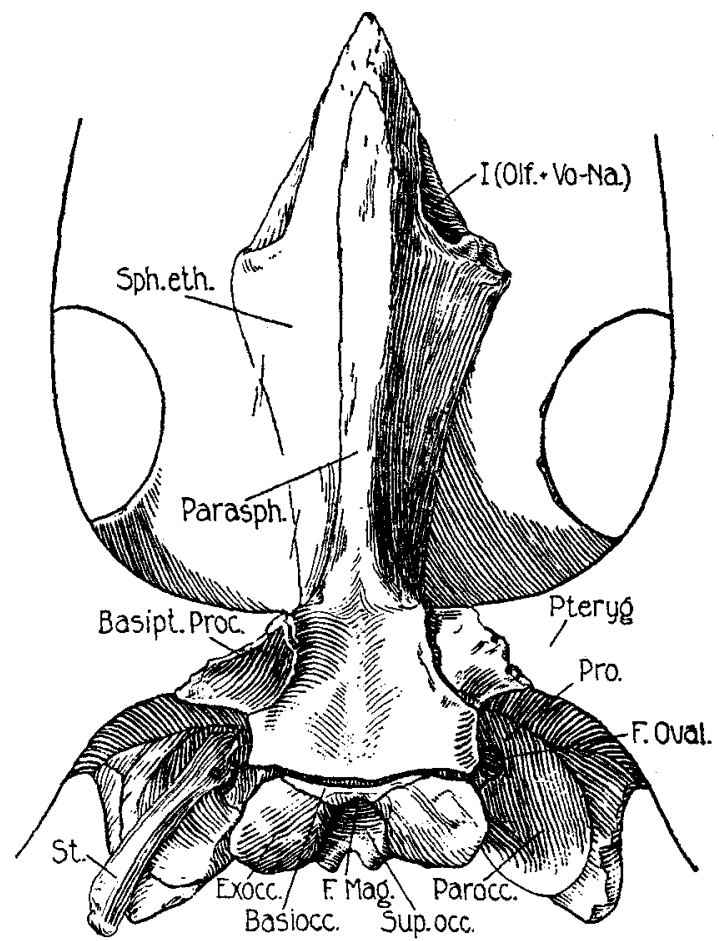

Fig. 2 Ventral aspect of Eryops brain ease in its relation to pterygoid bones and skull roof. The right stapes is in its natural position. I(Olf. $+\mathbb{V o}-\mathrm{Na}$.), opening for olfactory and vomeronasal nerves; Sph.eth., sphenethmoid bone; Parasph., parasphenoid bone; Basipt.Proc., basipterygoid process of basisphenoid bone; St., stapes; Exoce., exoceipital bone; Basiocc., basioccipital bone; F.Mag., foramen magnum; Sup.Occ., supraoceipital bone; Paroce., paroccipital bone; F.Oval., foramen ovale; Pro., prootic bone; Pteryg., pterygoid bone. $\times z$.

\footnotetext{
"These are the sphenethmoid, basisphenoid, lateral sphenoid, basioceipital, exoccipital, paroccipital, prootic, supraoceipital, parasphenoid, epipterygoid and stapes. The latter three bones, which do not directly take part in the endocranial and otocranial walls, are listed as brain case elements because of their close association with the brain case proper.
} 
mass (fig. 5) represents the fused sphenethmoid, basisphenoid and the lateral sphenoid bones. The lateral sphenoids, which had not been recognized previously, are evident as plates which extend from the basisphenoid region to the skull roof, and from the $V$ nerve foramen to the rostral part of the basisphenoid (optic nerve region). The other mass of bone is placed posteriorly and consists of the exoccipitals, paroccipitals, prootics and the supraoccipital. These elements form a housing for the internal ear and the covering for the upper and lateral parts of the brain stem. Save for the exoccipital, whose external limits are marked by suture lines, these elements are fused entirely to one another. The bony units which make up the bulk of the brain case, though they are not discrete, are characteristic stegocephalian features and there is no reason for not postulating their existence in Eryops. Precise boundaries between such elements, however, are largely uncertain.

If the accompanying semi-diagrammatic figures are consulted, some notion of the shape and relation of the bones may be obtained. It will be noticed that, except for sutures adjacent to the basioccipital element, no external sutures extend internally to the endocranial surface of the brain case. The lining of the cavity thus appears as a continuous and uninterrupted layer which surrounds the endocranium to the extent that none of the roofing bones of the skull impinges on the cavity. No lines other than occasional variable fracture lines could be detected on the endocranial surfaces either after careful cleaning or after subsequent treatment with acid. If this feature of fusion is borne in mind, the variations in the accounts of the earlier workers ${ }^{6}$ are, to a large extent, reconciled.

- Several details in the literature require comment:

a. Watson has described horizontal plates of the exoceipital lying above the basioccipital and forming the lower border of the foramen magnum. In the specimens observed, the basioccipital forms most of the lower region of the foramen; the exoccipital forms only the lateral portion of this region.

b. Broom and Watson apparently misled by the similar texture of the paraophenoid bone and the basipterygoid process, have considered that the latter process is overlapped ventrally by the parasphenoid. It is clear in several 
Sphenethmoid region. The heavily ossified sphenethmoid element of Eryops is an uncommon feature among amphibians. This bone together with the lateral sphenoids and the basisphenoid, which are fused with it, forms a complete osseous envelope for the midbrain and the more anterior brain parts. A similar bony envelope has been described for the Embolomeri : Paleogyrinus and Eogyrinus. Pfannenstiel has described in Mastodonsaurus the remains of a rudimentary sphenethmoid formed of calcified cartilage. In the more specialized Stegocephalia of the Triassic, such as Buettneria, Capitosaurus and Anaschisma, this element is entirely lacking. It is probable that in these forms the element was present, but as a cartilaginous structure unable to withstand fossilization. If the sphenethmoid lateral sphenoid basisphenoid mass in Eryops were to have been cartilaginous and were not preserved, the conditions found would be much like that of the more recent Stegocephalia. Progressive chondrification of the bony elements in the course of the evolution of the Stegocephalia may also account for the lack of, or rudimentary condition of, the bony auditory capsule and the basioccipital bone in the more highly developed species. $^{7}$ This same condition of extensive chondrification persists in the platybasic skulls of modern amphibians (Anura and Urodeles). Eryops together with the more primitive Embolomeri probably represents in its sphenethmoid a somewhat generalized amphibian character. The presence of an ossified sphenethmoid, lateral sphenoid and basisphenoid mass is an important feature in permitting a treatment of the endocranial anatomy, such as that which follows.

specimens that the parasphenoid neither covers the basipterygoid process nor articulates with the pterygoid.

c. There seems to be no evidence, even in specimens that are exceptionally clear, of a triradiate suture (the only suture so far described on the endocranial surface) bordering the supraoccipital, prootic and paroccipital elements.

d. Since suture lines do not delimit the paroccipital internally, it is impossible to say whether this element abuts on the cranial cavity or forms the rear wall of the labyrinth. In the specimens observed, the bony substance which has these relations may, with equal or greater probability, be a portion of the exoccipital.

'Pfannenstiel ('32) and Case ('33) have recently reviewed the evolutionary aspects of the chondrification of the stegocephalian brain case. 
Foramina. The brain case is perforated by several foramina which are reasonably identified by their location in the bony mass and by their relation to the subdivisions of the endocranial cavity. Four channels, two on a side, arise in common from the anterior portion of the endocranial cavity and perforate the sphenethmoid bone. They diverge as they extend anteriorly and pass toward a common concavity on the side of the anterior part of the sphenethmoid. The two perforations which are directed toward the mid-vomerine and olfactory regions, respectively, of each side, form a distinctive characteristic of Eryops. Broom has considered the inner and lower channel to be an excavation for an olfactory nerve, and the other to be a channel for a venous sinus. The postulation of a sinus is a doubtful suggestion, however, since such a structure is not to be found in recent forms. A more likely identification is suggested by the description of the vomeronasal and olfactory nerves of the frog and turtle by McCotter ('17). In these forms, there is little difference in size between the vomeronasal and olfactory nerves; the vomeronasal nerve courses mesially and inferiorly, while the olfactory nerve is laterally placed. Although both nerves typically leave the skull by the same foramen in the living forms, the similarity in the direction of nerves and in the direction of the canals in the sphenethmoid of Eryops suggests a better diagnosis. The lower medial channel might indicate the course of a vomeronasal nerve, while the upper and lateral canal might represent the course of the olfactory nerve. ${ }^{8}$ The development of Jacobson's organ in the lower living Tetrapoda intimates that the structure may have been even more important in the ancestral forms. The openings in the nasal region of the Rhachitomi: Dasyceps, Trematops and Trimerorhachis, and of the phyllospondylous Acanthostoma may have been associated with a vomeronasal organ, instead of the more generally assumed intermaxillary gland.

\footnotetext{
${ }^{8}$ Pfannenstiel looked favorably upon this interpretation in considering the sphenethmoid of Mastodonsaurus. In a dry skull of the frog Ceratophrys, the anterior portion of the endocranial wall is perforated by four foramina which may be related to the romeronasal and olfactory nerves.
} 
The optic nerve doubtless passed through a foramen on the side of the neurocranium at or near the region of fusion of the lateral sphenoid and sphenethmoid elements $(10 \pm \mathrm{em}$. posterior to the olfactory exit). A depression which may have given origin to the rectus group of eye muscles lies below the II nerve, and the endocranial wall in this region is characterized by excessive thinness. The frequency of fracture at this point of the skull in almost all the available specimens or the small size of the orbital nerve foramina has obscured all evidence of the III, IV and VI nerves. It is possible that these nerves may have found exit through the optic foramen.

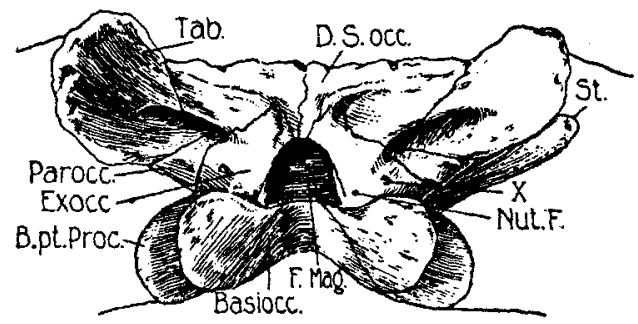

Fig. 3 Posterior aspect of brain ease of Eryops including tabulare and dermsupraoceipital of skull roof. $X$, opening for vagus group of nerves; Nut.F., foramen for nutrient vessels. $\times 2$.

The $V$ nerve exit is half the diameter of the foramen magnum and lies between the otic capsule and the lateral sphenoid element, just behind the epipterygoid bone.

A single foramen passes through the auditory capsule wall from the endocranial cavity to the internal ear region. Although the auditory nerve usually passes through several foramina in modern Amphibia (Miyawaki, '27), this does not seem to be the case with Eryops. The mode of exit of the VII nerve from the skull is not certain since no distinct foramen is evident. If the nerve left the endocranial cavity with the VIII nerve, its only exit from the auditory capsule would be through a cleft between the prootic and the basisphenoid bones behind the basipterygoid process. There is, however, no evidence of a characteristic foramen on the exterior of the 
skull, and it is possible that this nerve may have left the skull through the trigeminal foramen.

The fenestra ovale is an opening bounded by the exoccipital, paroccipital, prootic and basisphenoid. The foot of the stapes lies adjacent to the foramen in its apparently natural position in several specimens.

In modern Amphibia, the glossopharyngeo-vago-accessory group of nerves and the jugular vein pass through an opening in the exoccipital bone; in reptiles, there is, in addition, an opening for the hypoglossal nerve. ${ }^{9}$ In this respect, is Eryops similar to the reptiles or to the modern amphibians? Von Huene found no XII nerve foramen; Broom believed that he had found such an opening; Watson corrected Broom's interpretation of structures and maintained that there was no XII nerve opening.

Watson's interpretation seems better than that of Broom. In the postauditory region, there is a foramen which lies on the side of the medullar region of the endocranial surface of the neurocranium in advance of the foramen magnum. This has been traced through the exoccipital to a foramen on the rear surface of the bone below the exoccipital-paroccipital suture (not through the suture, as Watson stated). This structure, since it is the only channel in the postauditory region, must have transmitted the vagal group of nerves and the jugular vein; there is no additional foramen for a bypoglossal nerve.

Along the junction of the side and floor of the medullar portion of the endocranial surface are three indentations, two anterior and partly continuous and one posterior. If these structures had passed to the exterior of the skull, there would be little hesitation in referring to them as hypoglossal foramina. The pits, however, are not patent and do not extend to the exterior of the skull. A different diagnosis is thus required. Watson has recognized the anterior two indentations as a groove for a perilymphatic duct and the pos-

'In Gadow's posthumous work ('33), two chapters ( $X$ and $X I$ ) are devoted to the morphological relationships of the hypoglossal nerve. 

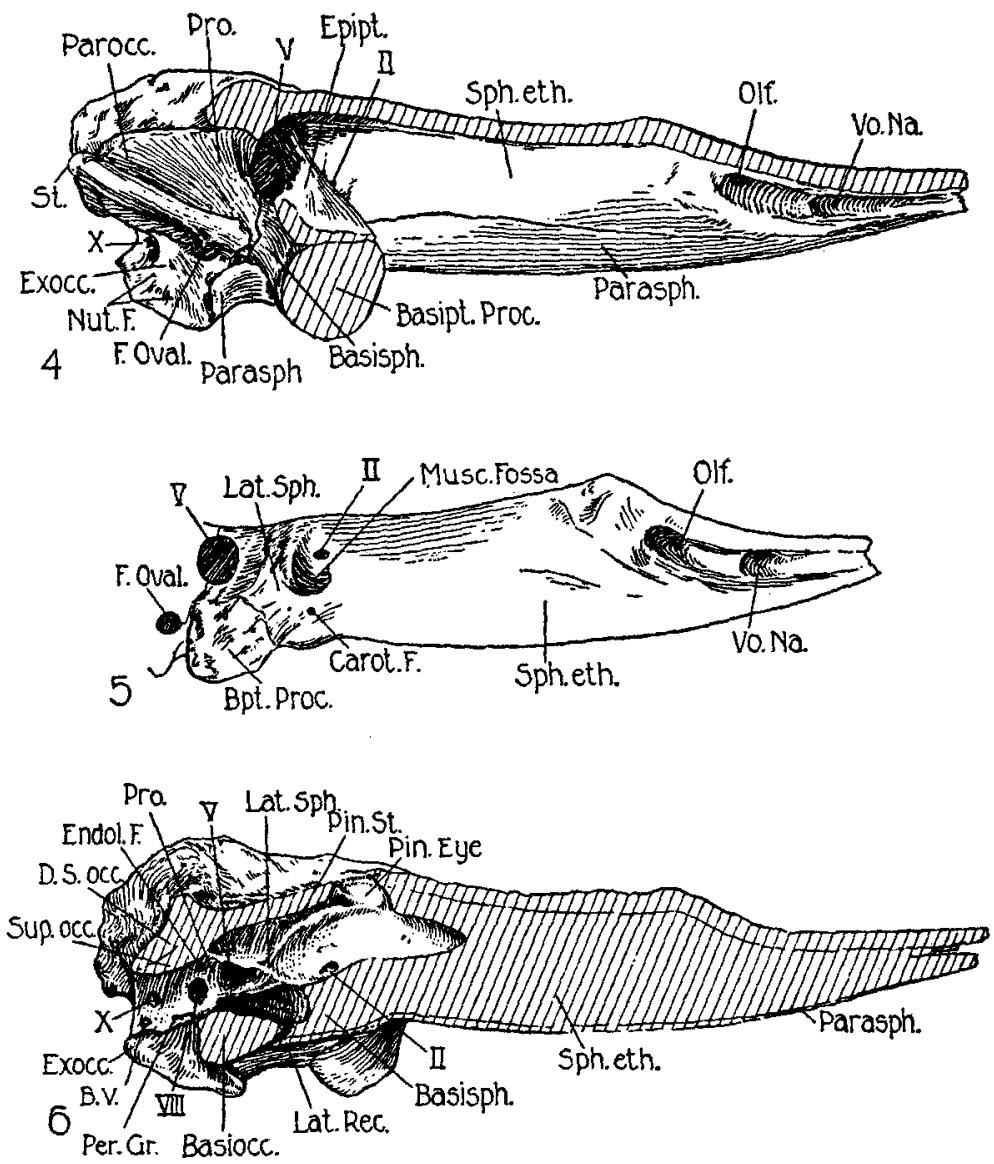

Fig. 4 Lateral aspect of Eryops neurocranium. Shaded areas represent section through skull roof and pterygoid articulations of the epipterygoid bone (Epipt.) and basipterygoid process. $V$, trigeminal foramen; $I I$, optic foramen; Biasisph., basisphenoid bone. $\times \frac{z}{}$.

Fig. 5 Sehema of the fused sphenethmoid, lateral sphenoids and basisphenoid bones as they appear from the front and side. Lat.Sph., lateral sphenoid bone; Musc.Fossa, fossa for rectus muscle attachment; Carot.F., carotid foramen. $\times . z$.

Fig. 6 Midsagittal section through brain case. Diagonally lined areas represent sectioned structures. Pin.Eye, socket for pineal eye; Pin.St., groove for pineal stalk; Endol.F., fossa for endolymphatic sac; B.V., vaseular channel; Per.Gr., groove for perilymphatic duct; Lat.Rec., lateral recess. $\times \xi$. 
terior as a foramen for a nutrient blood vessel. This interpretation is plausible, though not certain.

A small foramen passes through the lateral margin of the parasphenoid bone and the overlying basisphenoid bone, just anterior to the basipterygoid process. This foramen which leads forward and inward seems directed toward the endocranial cavity near the 'tweenbrain region, though its internal opening has not been demonstrated. In relation to the carotid foramen of modern Amphibia and other Stegocephalia (Case, '31), the foramen would seem to be identified with the internal carotid artery. Several inconstant foramina of pin-point size are evident on the posterior and lateral aspects of the exoccipital and on the anterior surface of the basipterygoid process. These must have been associated with nutrient vessels for the bone. The remaining perforations of the endocranial walls are the foramen magnum and the parietal foramen. The latter extends through the bony tegmen of the endocranial cavity as well as between the overlying parietal bones.

Bony framework of the parietal organ. A very common region of brain case fracture in Eryops specimens is that underlying the parietal foramen so that details of this region are not often nor well shown. In a recently discovered specimen (no. 14408, Univ. of Mich.), however, this region is quite clear and relatively undistorted. A unique character, which is shown in this fossil, is a modification of the brain case wall to house the parietal stalk and organ. A flange which arises on each lateral endocranial wall extends from the anterior margin of the trigeminal opening and describes a curved course (concave downward) to the posterior portion of the pineal region. The forward half of this flange, which nearly meets that of the opposite side in the midline, almost separates a small upper channel ( $3 \mathrm{~mm}$. in diameter) from the endocranial cavity proper, while the posterior part serves to separate the concavities for the midbrain and cerebrum. The anterior-most portion of the bony flange or septum becomes indistinguishable from the endocranial surface about the middle of the pineal foramen region. Above the front end 
of the flange and below the parietal opening, the walls of the foramen are excavated to form a small dorsoventrally flattened ovoid eavity which, in life, may have provided the socket for a pineal eye. A slight ridge indents the posterior portion of the concavity.

Ridges on the endocranial surface. In addition to the flange mentioned in connection with the pineal apparatus, three ridges radiate from the region in front of the trigeminal foramen. One of these extends backward and upward toward the supraoccipital element forming the upper, inner border of the $V$ foramen; another passes anteriorly to that part of the sphenethmoid lying below the cerebrum; while the last passes backward below the $V$ foramen to join the prootic bone. These four ridges, specializations of the lateral sphenoid and adjacent bones, serve to delimit the endocranial cavity into several regions presumably correlated with specific brain parts.

Pituitary region. On each side of the endocranial wall immediately below the cruciate marking made by the four endocranial ridges lies a rather extensive concavity which is designated as the lateral recess. The lateral recess, lying as it does below the vestibular region of each side, is continuous with the lower part of the endocranial cavity. The upper and posterior part of the recesses, which extend laterally more than $2 \mathrm{~cm}$. from the midline, are continuous with the cavity of the vestibule. The lateral masses of each side and the intervening portion of the endocranial cavity form a wide space which is non-committally referred to as the pituitary excavation. There are apparently no foramina leading into the concavity from the exterior. According to Watson, it may have been filled with cartilage during the life of the animal. Broom believed that the cavity might house a saccus vasculosus. Either suggestion is possible. It seems likely that a part of the space, between the lateral recesses at least, would be associated with the pituitary body.

The floor of the cerebrum slightly in front of the anterior wall of the pituitary excavation is very thin and the outer 
surface of the sphenethmoid bone in this region is indented to form a large fossa lying on the exterior of the brain case. This fossa (possibly comparable to the myodome of fishes) must have been the place of origin of the rectus group of orbital muscles. In several specimens which were fractured in this region, the thin bony walls were lacking so that the orbital muscle fossae were confluent across the midline. Broom, who doubtless had a specimen of this sort, described the anterior border of the pituitary excavation as a dorsum sellae, anterior to which lay a pituitary fossa having open sides. Von Huene had likewise referred to the structure as a hypophyseal fossa. Watson described a pituitary fossa consisting of two halves separated by a thin median ridge. The pituitary fossae of von Huene, Broom and Watson are in reality the paired depressions (possibly for rectus muscle attachment) on the exterior of the skull at the region where the sphenethmoid, lateral sphenoid and basisphenoid fuse. Because of the bony septa separating the muscular fossae from each other and from the endocranial cavity, the coneavities can in no way be related to the pituitary. According to the view outlined here, there is no evidence of a dorsum sellae so that the size or boundary of the pituitary body is uncertain.

Endolymphatic fossae. In the endocranial vault of Eryops, above and slightly in front of the internal auditory meatus, are small bilateral pits. A section through one of these proves it to be blind. Watson has considered the structure as an endolymphatic fossa. This view, which is supported here, may be extended to several other specimens.

There are several other species of fossil animals which show pitting of the skull in the auditory region. Two specimens of Cricotus (3001 and 9729, Univ. of Mich.) show similar pits in relatively the same position in the brain case roof. In one specimen, the pits are $4 \mathrm{~mm}$. across and nearly $2 \mathrm{~mm}$. deep; in the other, the pits, though evident, appear to have been covered by a membranous or cartilaginous shield. The matrix of these depressions is of a different constitution than 
either the general matrix or the bone. This may have been due to accumulations of otoconial crystals in an endolymphatic sac during life.

Edinger ('21) has described two evaginated processes in the anterior medullar region of an endocranial cast of Nothosaurus. These are called trochlear nerve exits, though it is not to be expected that a midbrain nerve leaves the skull in the medullar region. In the dinosaur Diplodicus, Osborn ('12) has described as endolymphatic fossae two fairly large and sharply marked depressions in the lateral endocranial wall above and posterior to the internal auditory meatus. In Tyranosaurus, there are peculiar pits in the endocranial walls of the anterior medullar region. Four of these are placed on each side of the hindbrain and one extends dorsally. These were considered as protrusions of dura, the lower three pairs marking the saccus vasculosus. Brown ('14) has described five elevations in the medullo-cerebellar region of the Trachodon endocranial cast. He likewise found protrusions of the endocranial cast in Anchiceratops and Triceratops. Osborn and Mook ('21) found similar structures in Camarasaurus.

It is suggested that the pits in the anterior medullar region of the cranial walls of the above forms be considered as depressions in which lie portions of the endolymphatic sacs. In addition to the similarity of location, it is known that: 1) The endolymphatic organ of modern amphibians and reptiles is a structure which is characterized by such variation in size, shape and relations (Dempster, '30) that the postulation of this organ in the above-mentioned fossils is not unwarranted. 2) The endolymphatic sac is known to mark the bony structure of the skull in certain modern animals; it penetrates a foramen in the gecko, while, in mammals, it lies in a small endocranial fossa.

The osseous labyrinth. Within the mass of bone formed by the prootic, paroccipital and exoccipital is the otocranial cavity, a space of irregular contour which is connected with the endocranial cavity proper by the auditory foramen and by a wide connection below with the lateral recess of the 
pituitary excavation. From the lateral aspect of the otocranial cavity, a short, cylindrical canal extends to the exterior of the skull to open as the fenestra ovale. Three small, irregular grooves show in the walls of the internal ear cavity and indicate the location of the semicircular canals. If the canals were separated at one time from the vestibular cavity proper by bony septa, these have entirely disappeared in the specimens studied so that only grooves in the wall remain. The osseous labyrinth where it is continuous with the lateral recess of the pituitary excavation gives no suggestion of markings which may have been associated with the lower part of the labyrinth.

\section{THE BRAIN CAST}

Osborn ('12), Edinger ('29) and others have recommended caution in the interpretation of endocranial casts of the lower Tetrapoda, since such casts, in addition to the brain, represent the cranial ganglia, the proximal portions of the nerves, the pituitary body and the pineal organ, the cranial blood vessels, the meninges and the endolymphatic sacs. The bony walls of the endocranial cavity are usually separated from the brain by a considerable space so that, as a consequence, they do not represent brain contours accurately. A comparison of the configuration of the brain with the endocranial cast of living forms, however, shows that, in some forms, the cast may conform with certain features of brain structure, while, in others, there is less similarity. The endocranial cast of Eryops seems to conform more closely with the major divisions of the reptilian and amphibian brain than casts from some of the modern forms (turtle and alligator).

The endocranial casts of Eryops represent the contour of the endocranial cavity from the foramen magnum region to the bifureation anteriorly of the channels ${ }^{10}$ for the olfactory

\footnotetext{
${ }^{20}$ Because of technical difficulties in preparing the casts of the slender channels, these have been reconstructed by means of sections, and this reconstruetion is added to the sketches of the endocranial cast as if the whole were obtained in a single cast.
} 


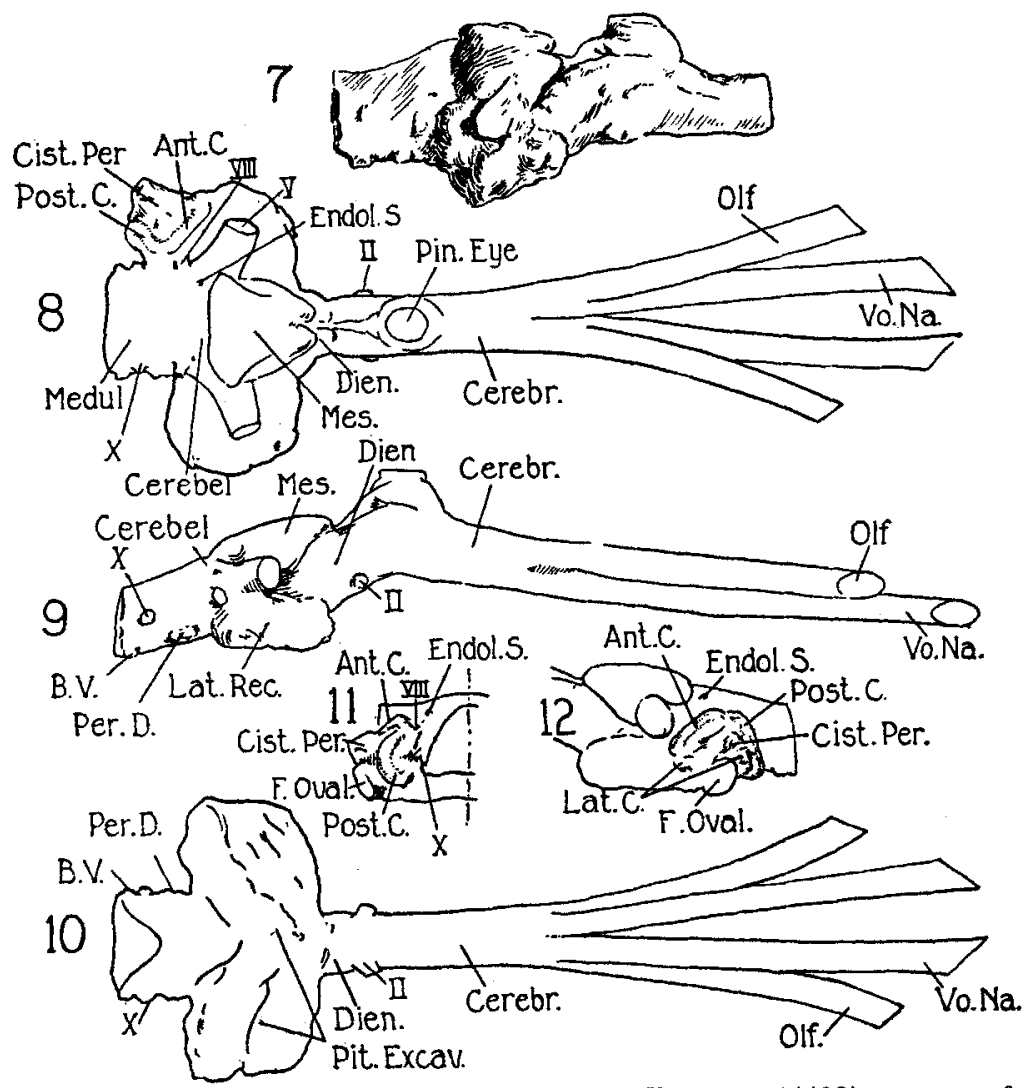

Fig. 7 Aetual brain cast of Eryops (Univ. Mich. no. 14408) as seen from right and slightly from above. $\times \frac{1}{2}$.

Fig. 8 Superior aspect of reconstructed brain cast and left internal ear cast. VIII, auditory nerve; Ant.C., anterior semieircular canal; Cist.Per., perilymphatic eistern; Post.C., posterior semicircular canal; Medul., medullar region; Cerebel., cerebellar region; Mes., mesencephalic region; Dien., 'tweenbrain region; Cerebr., cerebrum. $\times \frac{1}{2}$.

Fig. 9 Right side of brain cast. Per.D., perilymphatic duct region. $\times \frac{1}{2}$.

Fig. 10 Ventral aspect of brain cast. Pit.Excav, pituitary excavation and lateral recesses. $\times \frac{1}{2}$.

Fig. 11 Posterior aspect of left internal ear cast. $\times \frac{1}{2}$.

Fig. 12 Lateral aspect of left internal ear cast. Lat.C., lateral semicireular canal. $\times \frac{1}{2}$. 
and vomeronasal nerves. Probably, the most noticeable characteristic of the cast is that, unlike modern reptiles, the forebrain region is markedly constricted as compared with the posterior medullar and mesencephalic regions. As seen from the side, the cast shows a general sigmoid curvature from its posterior extremity to the anterior diverging processes. The cerebral region is slightly convex dorsally, while the brain stem is convex ventrally. Some portion of each of the main divisions of the brain is evident in the cast. The medullar region is a semicylindrical mass flattened below and convex from side to side above. The anteroposterior length is about equal to the width, while the height is about half the width. On the side of the medullar region just above the inferolateral margin are three slight protrusions arranged anteroposteriorly The anterior two are continuous, while the posterior is distinct. These are the casts of the perilymphatic groove and of a blood vessel entering the exoccipital (Watson). Somewhat further up on the side of the medullar region and in front of the protrusion marking the blood vessel is the cast of the foramen which transmits the IX, X and XI nerves and the jugular vein. Anteriorly, the sides of the medulla are produced forward and outward into cylindrical processes which represent the position of the $V$ nerve. Between the bases of these two diverticulae, the upper surface is noticeably flattened from side to side, and is slightly indicated by a perceptible transverse ridge which is thought to represent the position of the cerebellum. The cerebellum must have been small as in modern Amphibia, but nothing of its shape is evident. Two structures are found in the cerebellar region. Laterally, is a protrusion of the cast, representing the auditory nerve and extending toward the region of the internal ear, while more dorsally lies a very small tubercle. The latter, according to the interpretation suggested previously, represents an endolymphatic sac. The medullar region of the cast shows no evidence of trigeminal, facial and vagal ganglia or of a possible venous sinus system. If space is allowed these structures, the medulla proper must be con- 
sidered to have been much narrower than the cast might suggest. The midbrain region of the cast, as seen from above, is about as long and as wide as the medullar portion. This portion of the cast is suggestive of two pyriform masses, broader behind than before, and very slightly differentiated from one another. A distinct tuberosity on each side of the midline marks the anterior extremity of each of these lobes; posteriorly, a groove demarcates them from the cerebellum. The dorsal surfaces of both lobes are continuous in a surface which is slightly concave from side to side. The sides of the midbrain region extend downward to the diverticulae representing the $\mathrm{V}$ nerve. A deep groove below the midbrain separates the mesencephalon from the diencephalon.

Below the region of the cerebellum, $V$ nerve, midbrain and part of the diencephalon is a large mass which extends laterally to lie below the internal ear region. This is the cast of the large excavation flanking the pituitary region and the mass projects below the contour of the brain stem but slightly. On the lower surface of the brain, the lateral processes of each side are continuous across the midline and are fairly sharply differentiated from both the diencephalon and medulla. Certainly, the pituitary gland occupied a portion of it. It is possible, likewise, that the greater portion of the mass is correlated with a defect in fossilization which would not have been evident had the skull in a recent state been available for casting.

The diencephalon, the shape of which is roughly cylindrical, is markedly constricted as compared with the more posteriorly placed brain stem region. Its three major axes are approximately the same length. The posterior portion of the 'tweenbrain lies wedged between the midbrain, $\mathrm{V}$ nerve and the lateral expansions mentioned above. The contour of the pituitary body is not evident as a distinct unit of the cast, and it is assumed that this structure lay in the mass below the midbrain region. There is, likewise, no evidence that can be construed as marking the position of the internal carotid arteries, and it is obvious, in contrast with the configuration of casts of modern reptiles, that the carotid arteries 
were very small. Marking the anterior surface of the diencephalon ventrally are the paired evaginations which indicate the position of the optic nerves. On the superior surface of the 'tweenbrain are slight tubercles which are differentiated from the cerebrum by a perceptible groove. A most significant feature of Eryops, and something quite unique among brain casts of fossil forms, is a dorsal tubular diverticulum extending forward in the midline from the junction of the midbrain and 'tweenbrain region to expand in a somewhat globular mass lying upon the telencephalon. The strueture obviously represents a pineal stalk and the pineal eye. The cast of the pineal eye region is a dorsoventrally flattened globe which is marked off from the cerebrum and pineal stalk by slight grooves. The uppermost part of the globe is indented by margins of the pineal opening.

The cerebrum, as seen from above, is as much constricted as the diencephalon, and there is no deviation in outline which might separate the two brain parts. The dorsoventral axis in the region between the II nerve and the swelling for the pineal eye is somewhat greater than the more anterior dimension. In fact, the posterior portion of the cerebrum has an elliptical cross section with the dorsoventral axis exceeding the transverse axis. More anteriorly, the section represents an ellipse with its longer axis lying horizontally. Anteriorly, the cerebral region bifurcates into a right and a left portion, and the configuration is best made ont from the reconstruction of channels within the sphenethmoid bone. Very shortly in front of the bifurcation, each branch divides again into an upper outer branch, representing the olfactory nerve, and a lower medial branch, representing the vomeronasal nerve. The lower medial branches diverge very slightly and extend to their exit in the anterior portion of the sphenethmoid bone. The upper limbs diverge more noticeably as they lead toward their openings which are posterior to the first-mentioned branches. The circular cross section is approximately the same throughout each and all of the four channels. It is worth noting that the cast gives no indication of the presence 
or position of nerves for ocular muscles, the VII nerve or internal carotid arteries. ${ }^{11}$

The internal ear. The mass of the otocranial cast occupies somewhat less volume than the medulla or midbrain cast, and the size of the ear in relation to the size of the endocranial cast appears to be similar to that of the alligator and turtle. The cast shows some indication of the pars superior of the internal ear and the impressions of the fenestra ovale, but no indication of the phylogenetically more important pars inferior. Since the otocranial wall is continuous below with the endocranial contour, the lower part of the ear cast is continuous with the mass which extends laterally and below the brain stem region, and it is impossible to discern anything of the shape of the pars inferior. The depth of the lateral mass lying below the recognizable parts of the ear is so slight that it is impossible to conceive how the pars inferior could have a greater depth than exists in modern amphibians and lizards. Thus, an elongate lagena or cochlea is not indicated. It is impossible, however, to infer whether the pars inferior was more like that of the reptile or amphibian.

The cast of the fenestra ovale projects outward and very slightly downward and backward. It has about the same cross section as the cast of the $\mathrm{V}$ nerve.

The cast of the pars superior shows the complete contour of the anterior and posterior canals and possibly a suggestion of a horizontal canal. The ridges representing the canals have a width of nearly $3 \mathrm{~mm}$. and the contour is decidedly angular, more like that of modern reptiles (Retzius, 1884,

\footnotetext{
"Some dimensions of the most complete endocranial cast (Univ. of Mich., 14408) are as follows: Jength in millimeters, foramen magnum to $I$ nerve bifureation $=89$; medulla + cerebellum (dorsal) $=27$; medulla (ventral) $=18$; midbrain $=22$; diencephalon (dorsal) $=12$, (ventral) $=18$; cerebrum $=39$; parietal foramen $=9$; pineal eye $=17$; pineal stalk $=8$. Maximum-minimum width in millimeters, medulla $=26-24$; cerebellum $=31$; midbrain $=31-18$; diencephalon $=18-15$; cerebrum $=15-13$; pineal eye $=13$; pineal stalk $=3 ; \mathrm{V}$ nerve $=10$; II nerve $=4$. Depth in millimeters, medulla $=14$; midbrain $=8$; diencephalon $=14$; cerebrum $=16-11$; pineal eye $=7$; pineal stalk $=5-2.5 ;$ V nerve $=10$; II nerve $=2.5$.
} 
and Gray, '08) than of amphibians. The anterior canal extends obliquely downward, forward and outward from the crus commune region to the slight dilatation representing the ampullary region. The posterior canal extends downward, outward and slightly backward, and then, making a U-turn, extends inward to its utricular termination, showing no clear indication of the posterior ampulla. As seen from above, the angle between the two canals, instead of being obtuse as in amphibians, ${ }^{12}$ is very nearly $90^{\circ}$ as in modern reptiles. A very slight ridge lies behind and below the ampullary region of the anterior canal and this may indicate the ampullary portion of the horizontal canal. If so, nothing is shown of the course because of a protruded portion of the otocranial cast which lies between the anterior and posterior canals, completely covering the region of the horizontal canal and overriding the fenestra ovale region. This protrusion seems to indicate the position of a relatively large perilymphatic cistern.

It is possible that the otocranial walls may have been somewhat eroded to the extent that the perilymphatic cistern is slightly enlarged, and erosion may likewise account for the appearance of the anterior and posterior canals as ridges, rather than as canals separated from the vestibular region proper. It is again possible that this difference may have been due to unossified or cartilaginous portions of the otocranial walls. It is of interest to note the close similarity in the various characteristics between the casts of Fryops and the known structure of the ear of lizards and turtles. ${ }^{13}$

${ }^{2}$ In the Amphibia, the anterior and posterior canals often diverge from their common origin at the superior recess of the utriculus at a wide angle (in some of the urodeles, about $120^{\circ}$ ). The axes of the ampullae, however, when projected toward the midline, meet at more nearly a right angle.

${ }^{13}$ Dimensions of the ear from the best specimen (Univ. of Mieh,, 3000) are as follows: width of internal auditory meatus $=5.5 \mathrm{~mm}$.; diameter of canals $=3 \mathrm{~mm}$.; diameter of anterior ampulla $=3.5 \mathrm{~mm}$; length across anterior canal $=15 \mathrm{~mm}$. ; length across posterior canal $=14 \mathrm{~mm}$; length of fenestra ovale $=$ $6 \mathrm{~mm}$. ; width of fenestra ovale $=8 \mathrm{~mm}$.; depth of fenestra ovale $=88.5 \mathrm{~mm}$. 


\section{CONCLUSIONS}

The brain and internal ear of Eryops, as inferred from the endocranium and brain case, show similarities to those of modern amphibians and reptiles. In the linear arrangement of its subdivisions and in the slightly sigmoid curvature in the sagittal plane, the brain is typically that of a cold-blooded tetrapod. The shape and size of parts and the cranial nerves, although not identical with modern forms, are strictly compatible with the known characters of the simpler tetrapods. The narrowness of the cerebral region in contrast with that of living forms stamps the brain as decidedly primitive.

It is of interest to determine whether the characteristics of the endocranial anatomy are similar to those of amphibians or of reptiles. Features of unquestioned morphological value for differentiating the modern amphibian brain and ear from the reptilian are, as a rule, not the superficial characters with which we must deal here. Consequently, an evaluation must depend upon a group of minor features.

Of the more generalized features, the slightly sigmoid character of the endocranial contour as seen from the side is reptilian. The pyriform, narrow cerebrum grading anteriorly into the I nerves is likewise reptilian, as are the angular contour of the semicircular canals and the angle of divergence of the anterior and posterior canals.

In common with the Amphibia, Eryops presents small carotid foramina, a slightly developed cerebellum, a small pars inferior of the internal ear and the absence of a separate foramen for the hypoglossal nerve. The first three of these characters, however, are to a certain extent found in living reptiles other than the Crocodilia. The lack of a hypoglossal foramen is a distinct amphibian character.

Thus, it may be seen that the endocranial anatomy of Eryops shows one incontestable amphibian character, several which may be either amphibian or reptilian and still other characters which are distinctly reptilian. 
Some structures in Eryops are unlike those in modern forms. The pineal eye, which was much larger than in modern lizards, lay in a distinct socket, while its stalk was housed in a groove in the skull vault. The vomeronasal and olfactory nerves were transmitted through long channels penetrating the sphenethmoid bone instead of passing through foramina. The endolymphatic sacs, or portions of them, lay in small pits in the bony vault, thus differing from recent forms except perhaps the gecko. The endocranial contents were completely surrounded by bone, a feature unusual in living forms though it is found in the aberrant frog Ceratophrys. The floor of the vestibular cavity was lacking so that the vestibular and endocranial cavities were confluent. This may have been a defect of fossilization. These features are specializations which preclude Eryops from the ancestry of modern lines of amphibian and reptilian descent. Whether many of these features were similarly characteristic of related Stegocephalia cannot be inferred at present.

Other stegocephalians than Eryops may have had brains of the same general primitive type without the predominance of reptilian characters. These characters in Eryops may have been associated with the presumably terrestrial habits of the animal during its life rather than with its evolutionary status as a relatively primitive stegocephalian. The reptilelike characters may be accounted for by convergence toward the reptiles. In the development of the more generalized characters of the brain case and cast of Eryops, however, some insight is given into the ancestral condition of the primitive tetrapod.

When the Eryops brain cast is compared with brain casts of other fossil forms, closer similarities are evident with the cotylosaurs than with other groups. The cotylosaur Diadectes (Cope, 1886; von Huene; Edinger, '29) had a brain cast which resembles Eryops in the sigmoid curvature of the cast, the narrow cerebral region, the large pineal body, the wide midbrain region, the large $V$ nerve cast and the shape of the medullo-cerebellar region. The Eryops cast, however, has a 
relatively smaller telencephalon and in this feature, the brain must have been more primitive.

\section{LITERATURE CITED}

Branson, E. B. 1905 Structure and relationships of American Labyrinthodontidae. J. Geol., vol. 13, pp. 568-610.

BroILI, F. 1899 Ein Beitrag zur Kentniss von Eryops megacephala (Cope). Paleontographica, Bd. 46, S. 61-84.

Broom, R. 1913 Studies on the Permian temnospondylous stegocephalians of North America. Bull. Am. Mus. Nat. Hist., vol. 32, pp. 563-595.

Brown, B. 1914 Anehiceratops, a new genus of homed dinosaurs from the Edmonton Cretaceous of Alberta, with discussion of the origin of the ceratopsian crest and the brain easts of Anehiceratops and Trachodon. Bull. Am. Mus. Nat. Hist., vol. 33, pp. 539-548.

Case, E. C. 1911 Revision of the Amphibia and Pisces of Permian North America. Pub. Carnegie Inst. Wash., no. 146, pp. 1-179.

1931 Description of a new species of Buettneria, with a discussion of the brain case. Contrib. Mus. Paleont. Univ. Mich., vol. 3, pp. 187-206.

1933 Progressive chondrification in the Stegocephalia. Proc. Am. Phil. Soc., vol. 72, pp. 265-283.

1935 Deseription of a collection of associated skeletons of Trimerorhachis. Contrib. Mus. Paleont. Univ. Mich,, vol. 4, pp. 227-274.

COPE, E. D. 1886 On the structure of the brain and anditory apparatus of a theromorphous reptile of the Permian epoch. Proc. Am. Phil. Soc., vol. 23, pp. 234-238.

DEMPSTER, W. T. 1930 The morphology of the amphibian endolymphatic organ. J. Morph., vol. 50, pp. 71-126.

Edivakr, T. 1921 Ueber Nothosaurus. 1. Ein Steinkern der Schädelhöhle. Senckenbergiana, Bd. 3, S. 121-129.

1929 Die fossilen Gehirn. Ergeb. d. Anat. u. Entw-gesch., Bd. 28, S. 1-249.

G.dpow, H. F. 1933 The evolution of the vertebral column. Univ. Press, Cambridge.

Gray; A. A. 1908 The labyrinth of animals. London, vol. 2.

HOFIER, J. 1927 Archegosaurus decheni, Goldfuss, Untersuchung des Schädelbaues. Palaeont. Hungarica, vol. 2, pp. 109-130.

HURNe, F. voN 1912 Beiträge zur Kenntnis des Sehädels von Eryops. Anat. Anz., Bd. 41, S. 98-104.

1913 The skull elements of the Permian Tetrapoda in the Ameriean Museum of Natural History, New York. Bull. Am. Mus. Nat. Hist., vol. 32, pp. 315-386.

MCCoTrER, R. E. 1917 The vomeronasal apparatus in Chrysemys punctata and Rana catesbiana. Anat. Ree., vol. 13, pp. 51-67.

MIYAWAKI, S. 1927 Das Vorhandsein des Foramen acusticum medium an der Ohrkapsel von Anuren. Fol. Anat. Jap., Bd. 5, S. 313-325. 
Osborn, H. F. 1912 Crania of Tyrannosaurus and Allosaurus. Mem. Am. Mus. Nat. Hist., n.s., vol. 1, pp. 1-30.

OsBorn, H. F., AND C. C. MOOK 1921 Camarasaurus, Amphicoelius, and other sauropods of Cope. Mem. Am. Mus. Nat. Hist., n.s., vol. 3, pp. 249-387.

Prannenstiel, M. 1932 Gehirnkapsel und Gehirn fossiler Amphibien, Eine anatomische-biologische Studie. Monograph. z. Geol. u. Paleont., Ser. 2, S. 1-85.

hETZIUS, G. 1881-I884 Das Gehörorgan der Wirbeltiere. I. Das Gehörorgan der Fische und Amphibien. 221 S. II. Das Gehörorgan der Reptilien, Vögel und Säugetiere. $368 \mathrm{~S}$. Stoekholm.

WATSON, D. M. S. 1916 On the structure of the brain-case in certain lower Permian tetrapods. Bull. Am. Mus. Nat. Hist., vol. 35, pp. 611-636. 1920 The strueture, evolution and origin of the Amphibia, the 'orders' Rhachitomi and Stereospondyli. Phil. Trans. Roy. Soe. Lond., ser. B, vol. 209, pp. 1-73.

1926 The evolution and origin of the Amphibia. Phil. Trans. Roy. Soc. Lond., ser. B, vol. 214, pp. 189-257. 